\title{
Annual Report of the Korean Association of External Quality Assessment Service on Routine Hematology (2020)
}

\author{
Kibum Jeon ${ }^{1 \oplus}$, Young Min Kim ${ }^{2 \oplus}$, and Young Kyung Lee ${ }^{3 \oplus}$, on behalf of the Routine Hematology \\ Program of Korean Association of External Quality Assessment Service \\ ${ }^{1}$ Department of Laboratory Medicine, Hallym University Hangang Sacred Heart Hospital, Seoul; 2Department of Laboratory \\ Medicine, Hallym University Sacred Heart Hospital; ${ }^{3}$ Department of Laboratory Medicine, Hallym University Sacred Heart \\ Hospital, Hallym University College of Medicine, Anyang, Korea
}

Corresponding author:

Young Kyung Lee

Department of Laboratory Medicine, Hallym University Sacred Heart Hospital, Hallym University College of Medicine, 22 Gwanpyeong-ro 170 beongil, Dongan-gu, Anyang 14068, Korea Tel +82-31-380-3930

Fax +82-31-380-3934

E-mail lyoungk@hallym.or.kr

This is an Open Access article distributed under the terms of the Creative Commons Attribution Non-Commercial License (http://creativecommons.org/licenses/ by-nc/4.0) which permits unrestricted non-commercial use, distribution, and reproduction in any medium, provided the original work is properly cited.
Two trials were conducted with proficiency tests for complete blood count (CBC) and blood cell morphology as part of the 2020 Routine Hematology Program of the Korean Association of External Quality Assessment Service (KAEQAS). Three different control samples were sent for CBC testing, and two blood cell morphology images were posted on the KAEQAS website during each trial. The mean response rates of the 1,790 participating laboratories were $98.8 \%$ and $34.7 \%$ for CBC testing and blood cell morphology, respectively. The distribution of equipment for $\mathrm{CBC}$ testing was comparable to that of the previous year. The coefficient of variation (CV) ranges were determined as $2.9 \%-3.5 \%, 1.8 \%-2.8 \%, 1.4 \%-2.8 \%, 4.6 \%-5.5 \%$, and $5.2 \%-7.9 \%$ for white blood cell counts, red blood cell counts, hemoglobin, hematocrit, and platelet counts, respectively. The concordance rate of blood cell morphology tests ranged from $58.8 \%$ to $99.2 \%$. In 2020 , the number of participating laboratories was higher than that in 2019. The CVs of CBC results in 2020 were similar to those of 2019.

(Lab Med Qual Assur 2021;43:1-8)

Key Words Laboratory proficiency testing, Blood cell count, Blood cell morphology

\section{서론}

대한임상검사정도관리협회(협회) 신빙도조사사업은 2016년 차세대 신빙도조사사업으로 개편된 이후, 모든 항목의 신빙도조 사사업 전 과정이 협회 중앙에서 일관되게 시행되고 있으며, 올 해로 5년째를 맞이하고 있다[1]. 2020년 차세대 신빙도조사사 업의 일반혈액검사 프로그램은 전혈구 계산(complete blood count, $\mathrm{CBC}$ )과 세포형태(blood cell morphology), 2개 검사 항목에 대해 연 2회 시행하였으며, $\mathrm{CBC}$ 에는 백혈구 수(white blood cell count), 적혈구 수(red blood cell count), 혈색소 (hemoglobin), 적혈구용적률(hematocrit), 혈소판 수(platelet count)를 포함하여 시행하였다.

\section{재료 및 방법}

\section{1. 일반혈액검사 프로그램 구성 및 신빙도조사사업 시행과정} 일반혈액검사 프로그램에서는 $\mathrm{CBC}$ (백혈구 수, 적혈구 수, 혈색 소, 적혈구용적률, 혈소판 수)와 세포형태, 2개 검사항목을 대상 으로 각각 5 월과 10 월, 총 2 회 실시하였다. $\mathrm{CBC}$ 검사는 $\mathrm{CBC}-3 \mathrm{~K}$ Hematology Controls (R\&D System Inc., Minneapolis, MN, USA) 정도관리물질을 이용하였고, 각 회차마다 3 가지 농도의 정 도관리물질을 발송하였다. 세포형태검사는 각 회차마다 2 개의 세 
포사진을 간략한 임상소견과 함께 홈페이지에 게시하고 참가기관 에서 해당하는 세포형태검사 판독코드를 입력하도록 하였다.

정도관리물질은 계약 택배를 이용하여 발송하였는데, 1 회차는 5월 11일에, 2회차는 10 월 26일에 발송하였다. 검사결과는 신빙 도조사사업 홈페이지에 입력하도록 하였고, 입력기간 종료 후 입 력결과에 대해 데이터 오류를 검증한 후 통계분석을 시행하였다.

\section{2. 결과분석 및 보고서}

$\mathrm{CBC}$ 검사인 백혈구 수, 적혈구 수, 혈색소, 적혈구용적률, 혈소 판 수 결과는 전체 기관, 제조회사별, 측정기기별 통계분석을 시행 하였다. 측정기기별 분석에서는 유사모델인 경우 한 군으로 묶어 통계분석을 시행하였다.

통계분석은 평균, 표준편차(standard deviation, SD), 변이계 수(coefficient of variation, CV), 중간값, 최소값, 최대값을 구 하였으며, 각 기관에 대해 표준편차지수(standard deviation index, SDI)를 산정하였다[2]. 평균, SD, CV는 해당 분류별 분석 에서 75 percentile 값(Q3)과 25 percentile 값(Q1)의 차(Q3$\mathrm{Q} 1$, interquartile range, IQR)의 1.5배를 초과하여 Q1보다 낮거 나 $\mathrm{Q} 3$ 보다 높은 결과값(<Q1-1.5×IQR 또는 >Q3+1.5 $\times 1 \mathrm{QQR})$ 은 이상치(outlier)로 제거한 후 분석하였다[3]. 각 분류에 해당하는 기관 수가 10 개 미만인 경우에는 평균과 SD, CV, SDI를 구하지 않 았고, 기관 수가 3 개 미만인 경우에는 중간값도 구하지 않았다.

세포형태검사에 대한 분석은 각 세포별로 답한 기관 수와 백분 율을 구하였다. 분석한 결과는 참여기관 전체에 대한 '공통보고서' 와 각 기관별 결과에 대한 '기관별 보고서'로 작성하여 제공하고 홈페이지에서 직접 조회 및 출력할 수 있도록 하였다(Fig. 1A, B).
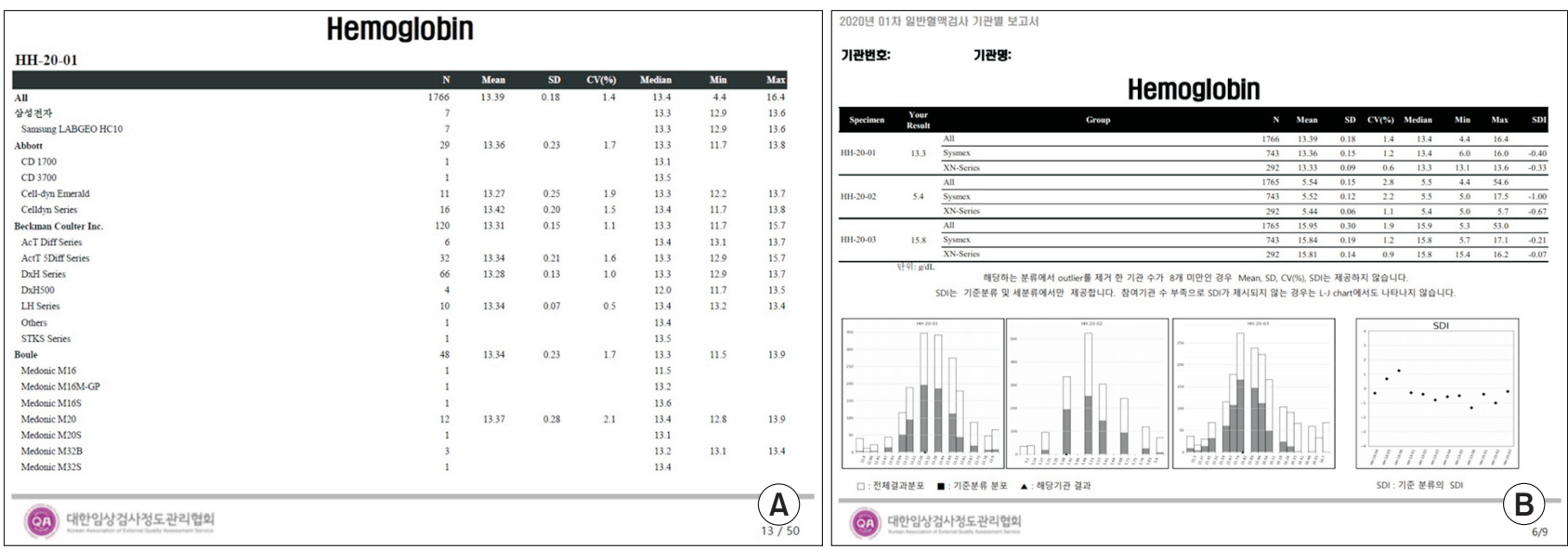

Fig. 1. Summary report of Routine Hematology program. (A) Summary of all participants. (B) Summary of each laboratory.

Table 1. Response rate of laboratories that participated in the proficiency tests performed under the Routine Hematology Program

\begin{tabular}{|c|c|c|c|c|c|c|c|}
\hline Test items & Trial & $\begin{array}{l}\text { Partici- } \\
\text { pants }\end{array}$ & $\begin{array}{c}\text { Sample delivery } \\
\text { date }\end{array}$ & $\begin{array}{l}\text { Participating } \\
\text { laboratories }\end{array}$ & Response date & $\begin{array}{c}\text { Participants } \\
\text { who } \\
\text { responded }\end{array}$ & $\begin{array}{c}\text { Response } \\
\text { rate }(\%)\end{array}$ \\
\hline \multirow[t]{3}{*}{ Complete blood count } & $1 s t$ & 1,827 & 2020. 5. 11 . & 1,782 & 2020. 5. 21 . & 1,766 & 99.1 \\
\hline & $2 n d$ & 1,839 & 2020. 10. 26. & 1,797 & 2020. 11. 5 . & 1,771 & 98.6 \\
\hline & Mean & 1,833 & & $1,789.5$ & & $1,768.5$ & 98.8 \\
\hline \multirow[t]{3}{*}{ Blood cell morphology } & 1 st & 1,827 & 2020. 5. 11. & 1,782 & 2020. 5. 21. & 621 & 34.8 \\
\hline & 2nd & 1,839 & 2020. 10. 26. & 1,797 & 2020. 11. 5 . & 620 & 34.5 \\
\hline & Mean & 1,833 & & $1,789.5$ & & 620.5 & 34.7 \\
\hline
\end{tabular}




\section{결과}

\section{1. 신빙도조사사업 참여기관}

2020년 일반혈액검사 프로그램은 총 1,833 기관이 신청하였 고, 1 회차에 1,782 기관, 2 회차에 1,797 기관에 검체를 배송하였다. $\mathrm{CBC}$ (백혈구 수, 적혈구 수, 혈색소, 적혈구용적률, 혈소판 수) 결 과를 회신한 기관은 1 회차 1,766 기관, 2 회차 1,771 기관으로 평균 결과 회신율은 $98.8 \%$ 였다. 세포형태검사 결과를 회신한 기관은 1 회차 621기관, 2회차 620기관으로 평균 결과 회신율은 34.7\%였 다(Table 1).

\section{Complete blood count 측정기기 사용현황}

결과를 회신한 기관에서 $\mathrm{CBC}$ 측정에 이용한 자동분석기 기는 제조사별로 분류하였을 때 Sysmex (Kobe, Japan)가 $42.2 \%$ 로 가장 많았고, Nihon Kohden Corp. (Tokyo, Japan) 11.6\%, Shenzhen Mindray Bio-Medical Electronics Co. Ltd.
(Shenzhen, China) 11.5\%, Siemens Healthcare Diagnostics Inc. (Tarrytown, NY, USA) 8.3\%, Horiba Medical (Montpellier, France) 8.0\%, Beckman Coulter Inc. (Miami, FL, USA) $6.6 \%$ 순이었으며, 1차에서 39기관, 2차에서 40 기관에서는 '기타'로 응답하였다(Table 2).

\section{Complete blood count}

백혈구 수는 평균값 $2,997 / \mu \mathrm{L}-21,733 / \mu \mathrm{L}$ 범위에서 전체기 관 CV가 2.9\%-3.5\%였고, 적혈구 수는 평균값 $2.269 \times 10^{6} / \mu \mathrm{L}-$ $5.201 \times 10^{6} / \mu \mathrm{L}$ 범위에서 전체기관 $\mathrm{CV}$ 가 $1.8 \%-2.8 \%$ 였다. 혈 색소는 평균값 $5.54 \mathrm{~g} / \mathrm{dL}-16.17 \mathrm{~g} / \mathrm{dL}$ 범위에서 전체기관 CV가 $1.4 \%-2.8 \%$ 였고, 적혈구용적률은 평균값 $17.36 \%-48.87 \%$ 범위 에서 전체기관 CV가 4.6\%-5.5\%였다. 혈소판 수는 평균값 81.1 $\times 10^{3} / \mu \mathrm{L}-473.7 \times 10^{3} / \mu \mathrm{L}$ 범위에서 전체기관 $\mathrm{CV}$ 가 $5.2 \%-7.9 \%$ 였다(Table 3).

Table 2. Equipment used for complete blood count testing

\begin{tabular}{|c|c|c|c|c|}
\hline Manufacturer & 1 st & 2nd & Mean & $\%$ \\
\hline Sysmex & 743 & 751 & 747.0 & 42.2 \\
\hline Nihon Kohden Corp. & 204 & 207 & 205.5 & 11.6 \\
\hline Shenzhen Mindray Bio-Medical Electronics Co. Ltd. & 201 & 204 & 202.5 & 11.5 \\
\hline Siemens Healthineers & 150 & 142 & 146.0 & 8.3 \\
\hline Horiba Medical & 140 & 142 & 141.0 & 8.0 \\
\hline Beckman Coulter Inc. & 120 & 115 & 117.5 & 6.6 \\
\hline Boule & 48 & 48 & 48.0 & 2.7 \\
\hline Orphee SA & 43 & 48 & 45.5 & 2.6 \\
\hline Abbott & 29 & 26 & 27.5 & 1.6 \\
\hline URIT Medical Electronic Co. Ltd. & 19 & 18 & 18.5 & 1.0 \\
\hline Erba Diagnostics & 9 & 8 & 8.5 & 0.5 \\
\hline Shenzhen Dymind Biotechnology Co. Ltd. & 8 & 9 & 8.5 & 0.5 \\
\hline Samsung Electronics Co. Ltd. & 7 & 7 & 7.0 & 0.4 \\
\hline Shenzhen Genius Electronics Co. Ltd. & 5 & 5 & 5.0 & 0.3 \\
\hline Dirui Industrial & 1 & 1 & 1.0 & 0.1 \\
\hline Others & 39 & 40 & 39.5 & 2.2 \\
\hline Total & 1,766 & 1,771 & 1768.5 & 100.0 \\
\hline
\end{tabular}

The instruments used were from the following companies: Sysmex (Kobe, Japan), Nihon Kohden Corp. (Tokyo, Japan), Shenzhen Mindray Bio-Medical Electronics Co. Ltd. (Shenzhen, China), Siemens Healthcare Diagnostics Inc. (Tarrytown, NY, USA), Horiba Medical (Montpellier, France), Beckman Coulter Inc. (Miami, FL, USA), Boule (Spånga, Sweden), Orphee SA (Geneva, Switzerland), Abbott (Abbott Park, IL, USA), URIT Medical Electronic Co. Ltd. (Guilin, China), Erba Diagnostics (Miami, FL, USA), Shenzhen Dymind Biotechnology Co. Ltd. (Shenzhen, China), Samsung Electronics Co. Ltd. (Suwon, Korea), Shenzhen Genius Electronics Co. Ltd. (Shenzhen, China), and Dirui Industrial (Changchun, China). 
Table 3. Proficiency test results for complete blood count

\begin{tabular}{|c|c|c|c|c|c|c|c|c|}
\hline Item & $\begin{array}{c}\text { No. of } \\
\text { participants }\end{array}$ & Median & Min & Max & Mean \pm SD & CV (\%) & $\begin{array}{l}\text { No. except } \\
\text { outliers }\end{array}$ & $\begin{array}{l}\text { Outliers } \\
(\%)\end{array}$ \\
\hline \multicolumn{9}{|l|}{$1 s t$} \\
\hline \multicolumn{9}{|l|}{ WBC count } \\
\hline $\mathrm{HH}-20-01$ & 1,764 & 7.47 & 0.08 & 76.00 & $7.458 \pm 0.223$ & 3.0 & 1,659 & 6.0 \\
\hline $\mathrm{HH}-20-02$ & 1,763 & 3.00 & 1.01 & 30.00 & $2.997 \pm 0.104$ & 3.5 & 1,692 & 4.0 \\
\hline $\mathrm{HH}-20-03$ & 1,763 & 21.78 & 0.22 & 27.20 & $21.733 \pm 0.754$ & 3.5 & 1,679 & 4.8 \\
\hline \multicolumn{9}{|l|}{$\mathrm{RBC}$ count } \\
\hline $\mathrm{HH}-20-01$ & 1,763 & 4.71 & 0.00 & 6.67 & $4.711 \pm 0.090$ & 1.9 & 1,675 & 5.0 \\
\hline $\mathrm{HH}-20-02$ & 1,763 & 2.27 & 0.00 & 5.83 & $2.269 \pm 0.051$ & 2.2 & 1,700 & 3.5 \\
\hline $\mathrm{HH}-20-03$ & 1,762 & 5.00 & 0.95 & 7.35 & $4.996 \pm 0.095$ & 1.9 & 1,679 & 4.7 \\
\hline \multicolumn{9}{|l|}{ Hemoglobin } \\
\hline $\mathrm{HH}-20-01$ & 1,766 & 13.4 & 4.4 & 16.4 & $13.39 \pm 0.18$ & 1.4 & 1,626 & 7.9 \\
\hline $\mathrm{HH}-20-02$ & 1,765 & 5.5 & 4.4 & 54.6 & $5.54 \pm 0.15$ & 2.8 & 1,715 & 2.8 \\
\hline $\mathrm{HH}-20-03$ & 1,765 & 15.9 & 5.3 & 53.0 & $15.95 \pm 0.30$ & 1.9 & 1,703 & 3.5 \\
\hline \multicolumn{9}{|l|}{ Hematocrit } \\
\hline $\mathrm{HH}-20-01$ & 1,762 & 42.6 & 5.3 & 55.5 & $42.08 \pm 2.29$ & 5.4 & 1,732 & 1.7 \\
\hline $\mathrm{HH}-20-02$ & 1,761 & 17.9 & 2.6 & 80.2 & $17.70 \pm 0.97$ & 5.5 & 1,725 & 2.0 \\
\hline $\mathrm{HH}-20-03$ & 1,761 & 48.7 & 4.2 & 99.9 & $48.07 \pm 2.59$ & 5.4 & 1,710 & 2.9 \\
\hline \multicolumn{9}{|l|}{ Platelet count } \\
\hline $\mathrm{HH}-20-01$ & 1,763 & 242 & 61 & 6,275 & $241.4 \pm 12.6$ & 5.2 & 1,690 & 4.1 \\
\hline $\mathrm{HH}-20-02$ & 1,762 & 82 & 48 & 8,492 & $81.7 \pm 5.8$ & 7.1 & 1,673 & 5.1 \\
\hline $\mathrm{HH}-20-03$ & 1,762 & 472 & 83 & 4,628 & $471.0 \pm 24.3$ & 5.2 & 1,693 & 3.9 \\
\hline \multicolumn{9}{|l|}{ 2nd } \\
\hline \multicolumn{9}{|l|}{ WBC count } \\
\hline $\mathrm{HH}-20-04$ & 1,768 & 7.72 & 1.57 & 22.20 & $7.740 \pm 0.247$ & 3.2 & 1,653 & 6.5 \\
\hline $\mathrm{HH}-20-05$ & 1,768 & 3.04 & 0.82 & 99.99 & $3.046 \pm 0.087$ & 2.9 & 1,590 & 10.1 \\
\hline $\mathrm{HH}-20-06$ & 1,767 & 21.69 & 2.17 & 31.40 & $21.663 \pm 0.672$ & 3.1 & 1,656 & 6.3 \\
\hline \multicolumn{9}{|l|}{ RBC count } \\
\hline $\mathrm{HH}-20-04$ & 1,768 & 4.60 & 0.60 & 5.81 & $4.603 \pm 0.084$ & 1.8 & 1,667 & 5.7 \\
\hline $\mathrm{HH}-20-05$ & 1,768 & 2.27 & 1.33 & 9.99 & $2.280 \pm 0.064$ & 2.8 & 1,729 & 2.2 \\
\hline $\mathrm{HH}-20-06$ & 1,767 & 5.21 & 0.80 & 7.11 & $5.201 \pm 0.098$ & 1.9 & 1,667 & 5.7 \\
\hline \multicolumn{9}{|l|}{ Hemoglobin } \\
\hline $\mathrm{HH}-20-04$ & 1,771 & 13.6 & 5.3 & 17.8 & $13.63 \pm 0.20$ & 1.5 & 1,679 & 5.2 \\
\hline $\mathrm{HH}-20-05$ & 1,771 & 5.7 & 4.3 & 99.9 & $5.71 \pm 0.16$ & 2.8 & 1,710 & 3.4 \\
\hline $\mathrm{HH}-20-06$ & 1,770 & 16.1 & 5.7 & 22.3 & $16.17 \pm 0.30$ & 1.9 & 1,709 & 3.4 \\
\hline \multicolumn{9}{|l|}{ Hematocrit } \\
\hline $\mathrm{HH}-20-04$ & 1,767 & 42.5 & 5.2 & 58.6 & $42.08 \pm 2.06$ & 4.9 & 1,705 & 3.5 \\
\hline $\mathrm{HH}-20-05$ & 1,767 & 17.4 & 10.5 & 99.9 & $17.36 \pm 0.79$ & 4.6 & 1,732 & 2.0 \\
\hline $\mathrm{HH}-20-06$ & 1,766 & 49.4 & 7.0 & 98.3 & $48.87 \pm 2.29$ & 4.7 & 1,686 & 4.5 \\
\hline \multicolumn{9}{|l|}{ Platelet count } \\
\hline $\mathrm{HH}-20-04$ & 1,767 & 238 & 73 & 2,200 & $238.6 \pm 15.0$ & 6.3 & 1,676 & 5.1 \\
\hline $\mathrm{HH}-20-05$ & 1,767 & 80 & 55 & 9,999 & $81.1 \pm 6.4$ & 7.9 & 1,681 & 4.9 \\
\hline $\mathrm{HH}-20-06$ & 1,766 & 475 & 82 & 4,380 & $473.7 \pm 25.4$ & 5.4 & 1,664 & 5.8 \\
\hline
\end{tabular}

Abbreviations: SD, standard deviation; CV, coefficient of variation; WBC, white blood cell; RBC, red blood cell. 


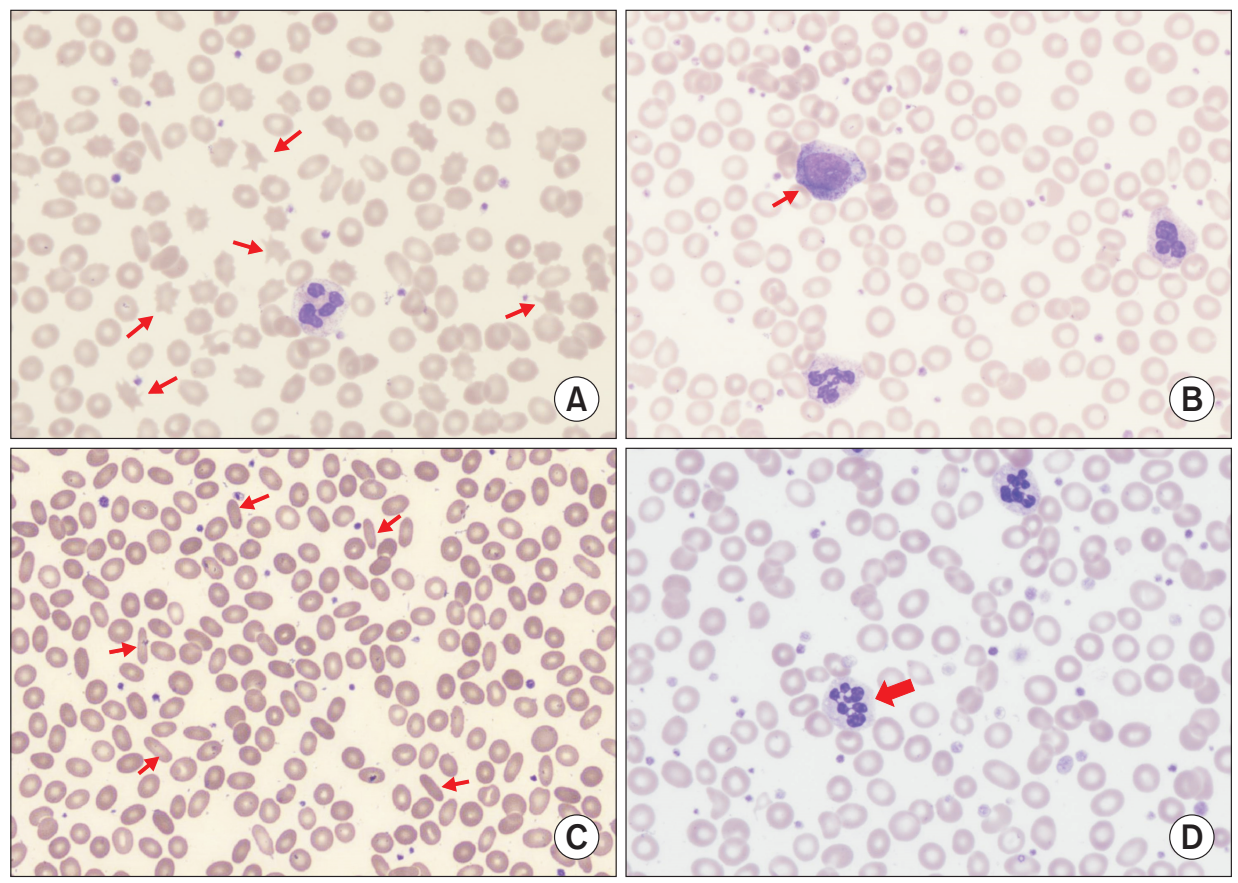

Fig. 2. Cell morphology pictures posted for the proficiency tests of Blood cell morphology. (A) HHI20-01 acanthocyte (spur cell) (arrows). (B) HHI-20-02 promyelocyte (arrow). (C) HHI-20-03 ovalocyte (elliptocyte) (arrows). (D) HHI20-04 hypersegmented neutrophil (arrow).

\section{4. 세포형태}

세포형태는 매 회차마다 2 개의 사진을 게시하였다. 출제 의도 와 응답기관의 $80 \%$ 이상에서 일치하는 결과를 기준으로 '적합 (acceptable),' '부적합(unacceptable)'으로 평가하였다. 1회차 HHI-20-01는 acanthocyte (spur cell)에 93.2\%의 일치율을 보 였으나 HHI-20-02는 promyelocyte에 $58.8 \%$ 의 일치율을 보였 다(Fig. 2A, B). 이로 인해 HHI-20-02에 대해서는 $30.1 \%$ 의 응답 률을 보인 myelocyte와 promyelocyte 두 가지 모두를 '적합'으 로 평가하였다. 2회차 HHI-20-03은 ovalocyte (elliptocyte)에 $99.2 \%$ 의 일치율을 보였으며, HHI-19-04는 hypersegmented neutrophil에 96.6\% 일치율을 보였다(Table 4, Fig. 2C, D).

\section{고찰}

2016년 차세대 신빙도조사사업 시행에 따라 연 2차에 걸쳐 매 회차마다 $\mathrm{CBC}$ 는 정도관리물질 3 개, 세포형태는 사진 2개씩 시행 하고 있으며[1], 2020년은 차세대 신빙도조사사업 체계로 시행된 다섯 번째 해였다.

2020 년 일반혈액검사 프로그램에는 1,2 회차 평균 $1,768.5$ 기관 이 응답하여 2019 년의 평균 1,740 기관에 비해 28.5 기관이 늘어 $1.6 \%$ 의 증가를 보였다[4] (Fig. 3). 결과 회신율은 $\mathrm{CBC}$ 는 $98.8 \%$ 로, 세포형태는 34.7\%로 예년과 비슷한 수준이었다[4].
2016년 차세대 신빙도조사사업 이후 변화된 체계에 따라 모든 프로그램에 대해 정도관리물질의 발송부터 결과입력, 보고서 발송 까지 전 과정을 협회 중앙에서 일관되게 관리, 진행하고 있다[1]. 검체 발송은 다른 프로그램의 정도관리물질과 함께, 예약된 택배 로 진행되었다. 하절기에는 기온이 상승함에 따라 배송하는 동안 검체의 용혈이나 변성이 발생되기 쉬워 이 시기를 피하여 1 회차는 5 월 11 일에, 2 회차는 10 월 26 일에 발송하여 검체의 안정성을 높 이고자 하였다.

검체 수령 시 각 기관에서는 협회 차세대 신빙도조사사업 홈페 이지에서 검체 접수를 한 후, 검사를 시행하고 결과를 홈페이지에 직접 입력한 후, 최종 전송을 하여야 결과가 전송되도록 하였다. 입력기간 종료 후 입력결과에 대하여 오류를 점검하고, 통계분석 을 시행하였으며, 결과통보 역시 차세대 신빙도조사사업 홈페이 지에서 참여기관별로 직접 조회 및 출력할 수 있도록 하였다. 결 과보고서는 공통보고서와 기관별 보고서 두 가지 형태로 제공하 였으며, 공통보고서에는 전체기관, 그리고, 제조사별, 기기별 통계 를 제공하였다. 기관별 보고서에서는 각 기관의 결과값과 전체, 그 리고 기관에서 사용하는 기기의 제조사, 기기분류에 따른 통계값과 $\mathrm{SDI}$ 를 제공하였으며, 전체기관 및 동일 제조사를 사용하는 기관들 에서 해당 기관의 결과값의 위치를 히스토그램으로 제공하고, 해당 기관의 SDI의 누적분포를 그래프로 표시하여 제공하였다(Fig. 1).

통계분석 시 소수점 표시 착오 등 입력오류로 판단되는 것은 수 
Table 4. Proficiency test results for blood cell morphology

\begin{tabular}{|c|c|c|c|}
\hline Trial & Code & Morphology & No. $(\%)$ \\
\hline \multirow[t]{6}{*}{ HHI-20-01 } & Total & & $621(100.0)$ \\
\hline & 457 & Acanthocyte (spur cell) & $579(93.2)$ \\
\hline & 453 & Schistocyte & $19(3.1)$ \\
\hline & 458 & Burr cell & $17(2.7)$ \\
\hline & 456 & Sickle cell & $5(0.8)$ \\
\hline & 103 & Myelocyte & $1(0.2)$ \\
\hline \multirow[t]{13}{*}{$\mathrm{HHI}-20-02$} & Total & & $621(100.0)$ \\
\hline & 102 & Promyelocyte & $365(58.8)$ \\
\hline & 103 & Myelocyte & $187(30.1)$ \\
\hline & 224 & Monocyte & $22(3.5)$ \\
\hline & 328 & Large granular lymphocyte & $18(2.9)$ \\
\hline & 329 & Atypical lymphocyte & $9(1.4)$ \\
\hline & 327 & Lymphocyte & $7(1.1)$ \\
\hline & 223 & Immature monocyte & $4(0.6)$ \\
\hline & 693 & Blast & $3(0.5)$ \\
\hline & 104 & Metamyelocyte & $3(0.5)$ \\
\hline & 457 & Acanthocyte (spur cell) & $1(0.2)$ \\
\hline & 471 & Macrocyte & $1(0.2)$ \\
\hline & 115 & Myeloblast with Auer rod & $1(0.2)$ \\
\hline \multirow[t]{6}{*}{ HHI-20-03 } & Total & & $620(100.0)$ \\
\hline & 452 & Ovalocyte (elliptocyte) & $615(99.2)$ \\
\hline & 456 & Sickle cell & $2(0.3)$ \\
\hline & 453 & Schistocyte & $1(0.2)$ \\
\hline & 454 & Spherocyte & $1(0.2)$ \\
\hline & 434 & Normal red blood cell (normal red blood cell) & $1(0.2)$ \\
\hline \multirow[t]{3}{*}{$\mathrm{HHI}-20-04$} & Total & & $620(100.0)$ \\
\hline & 114 & Hypersegmented neutrophil & $599(96.6)$ \\
\hline & 106 & Segmented neutrophil & $21(3.4)$ \\
\hline
\end{tabular}

기로 제외하고, 이상치에 해당하는 결과값은 Turkey의 'box-plot 방식을 이용한 사분위법'의 이상치 제거를 적용하여 통계분석에서 제외하였다[3]. 통계범위에 들어오는 기관만을 대상으로 평균과 $\mathrm{SD}, \mathrm{CV}$ 를 계산하였으며, 각 기관의 평가결과는 $\mathrm{SDI}$ 로 제시하였 다. 이에 따라 일반혈액검사의 통계분석 제외기관은 1 회차에서는 $1.7 \%-7.9 \%, 2$ 회차에서는 2.0\%-10.1\%로 예년과 비슷한 수준이 었으며, 2회차 HH-20-05의 백혈구 수가 $10.1 \%$ 로 다소 높았다[4] (Table 3).

$\mathrm{CBC}$ 에 사용된 기기의 현황은 Sysmex (Japan)가 $42.2 \%$ 로 가
장 많았고, 다음으로, Nihon Kohden Corp. (Japan), Shenzhen Mindray Bio-Medical Electronics Co. Ltd. (China), Siemens Healthcare Diagnostics Inc. (USA), Horiba Medical (France), Beckman Coulter Inc. (USA) 등이 분포하여 주요 사용기기의 분포는 예년과 유사하였으며, 참가기관 수가 증가되었음에도 불구 하고 '기타'로 응답한 기관 수는 줄어들었다 $[1,4]$.

수행능 측면에서 $\mathrm{CBC}$ 의 백혈구 수, 적혈구 수, 혈색소, 적혈 구용적률, 혈소판 수의 CV는 각각 $2.9 \%-3.5 \%, 1.8 \%-2.8 \%$, $1.4 \%-2.8 \%, 4.6 \%-5.5 \%, 5.2 \%-7.9 \%$ 범위로, 백혈구 수의 CV 


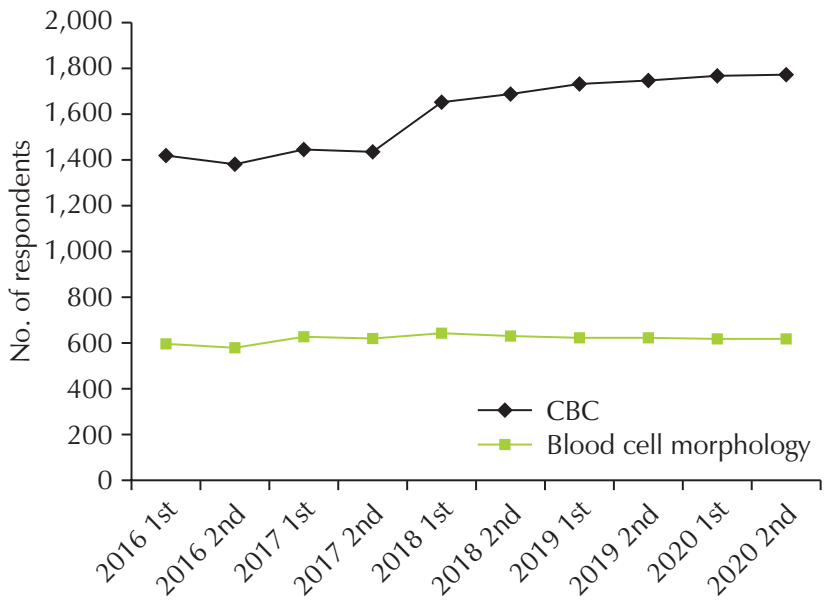

Fig. 3. The trends of the numbers of participants who responded in complete blood count $(\mathrm{CBC})$ and blood cell morphology from 2016 to 2020.
는 2016년 이후 지속적으로 감소하는 경향을 보이고 있으며, 다 른 검사항목은 예년과 비슷한 분포였다[1,4] (Fig. 4). 세포형태는 1회차의 HHI-20-01의 acanthocyte (spur cell), 2회차 HHI-2003의 ovalocyte (elliptocyte), HHI-20-04의 hypersegmented neutrophil에 대해 각각 $93.2 \%, 99.2 \% 96.6 \%$ 의 높은 일치율을 보였다. HHI-20-02은 promyelocyte가 58.8\%로 낮은 일치율을 보였는데, myelocyte가 $30.1 \%$ 로 그 다음으로 높은 응답률을 보 여 의견이 나누어지는 모습을 보였다. 이는 두 세포의 형태학적 구 분이 어려울 수 있음을 보여준다.

2020년 일반혈액검사 프로그램은 2016년 차세대 신빙도조사사 업이 시행됨에 따라 전 과정이 전체 프로그램과 함께 협회 중앙에서 일괄 시행되었으며, 참여기관은 지속적으로 증가하는 추세이고, 수 행능 측면에서 백혈구 수는 지속적으로 CV가 감소하는 양상을 보이 며, 그 외 다른 검사항목의 수행능은 예년과 비슷한 결과를 보였다.
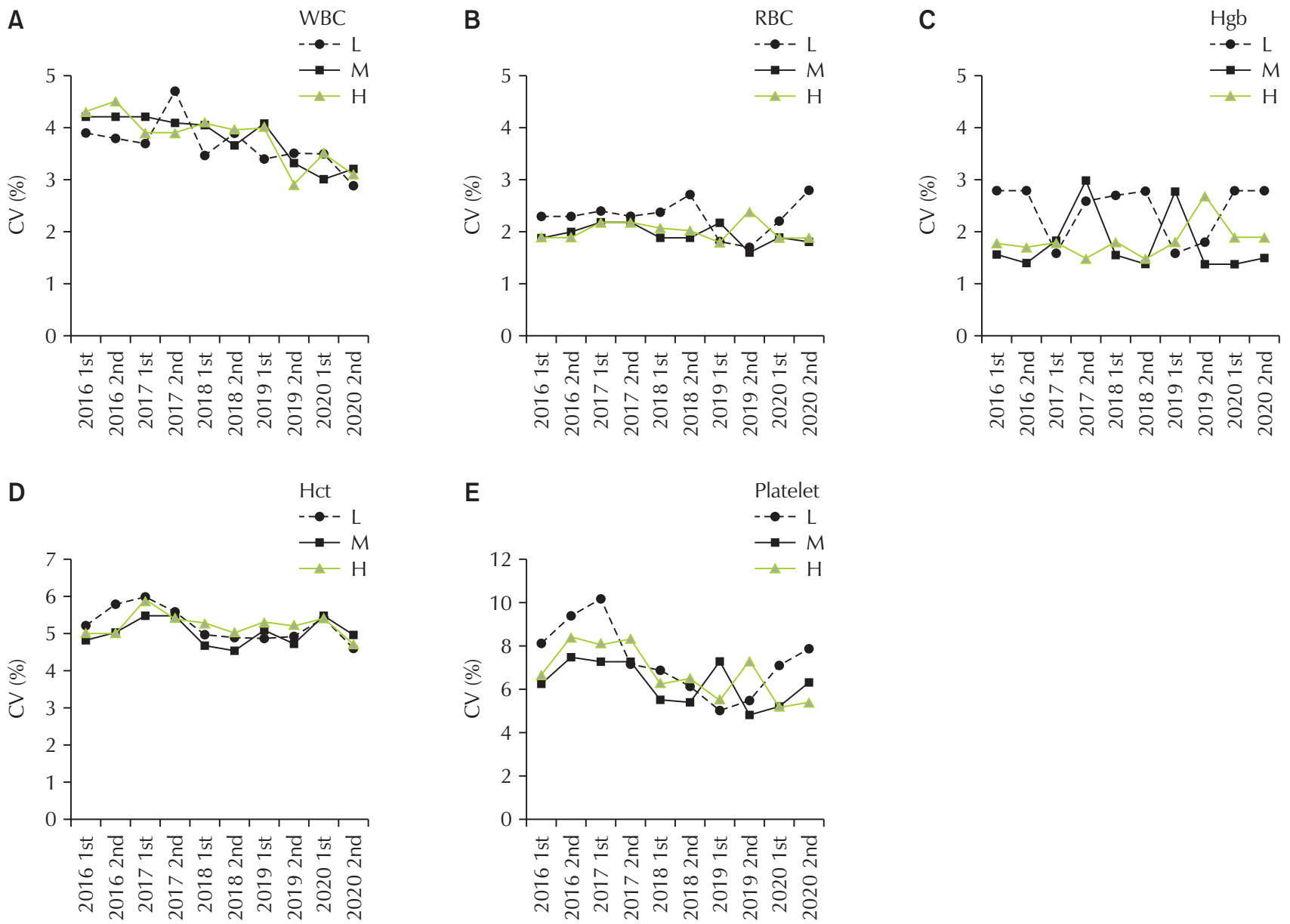

Fig. 4. The trends of the coefficients of variation (CVs) of complete blood count (CBC) parameters from 2016 to 2020. (A) White blood cell count (WBC). (B) Red blood cell count (RBC). (C) Hemoglobin (Hgb). (D) Hematocrit (Hct). (E) Platelet count. Abbreviations: L, low level; M, middle level; $\mathrm{H}$, high level. 


\section{ORCID}

Kibum Jeon

$$
\text { https://orcid.org/0000-0002-1333-5366 }
$$

Young Min Kim https://orcid.org/0000-0002-4735-7213

Young Kyung Lee https://orcid.org/0000-0003-0433-8028

\section{REFERENCES}

1. Lee YK; Routine Hematology Program, Korean Association of External Quality Assessment Service. Annual report on the external quality assessment scheme for routine hematology in Korea (2016). J Lab Med Qual Assur 2017;39:5360.

2. Klee GG, Westgard JO. Quality management. In: Burtis CA, Ashwood ER, Bruns DE, editors. Teitz textbook of clinical chemistry and molecular diagnostics. 5th ed. St. Louis (MO): Elsevier Saunders, 2012:163-203.

3. Turkey JW. Exploratory data analysis. Reading (MA): Addison-Wesley, 1977.

4. Lee YK, Kim YM. Annual report of the Korean Association of External Quality Assessment Service on routine hematology (2019). Lab Med Qual Assur 2020;42:55-62. 